\title{
Research on the Public Promotion Translation of Non-material Cultural Heritage
}

\author{
Yulan Wang \\ Shandong Youth University of Political Science, Jinan, Shandong, 250000
}

Keywords: non-material cultural heritage; translation; public promotion

\begin{abstract}
China is a multi-ethnic country with a long history. Its intangible cultural heritage is splendid. Among them, Anhui Province shows its unique charm of Chinese culture with its unique emblem of Huifeng. However, due to the communication barriers caused by the differences between Chinese and foreign languages and cultures, it has not been better understood by the world. In this regard, the paper will use the theory of variable translation as a theoretical basis, and refer to seven means of increasing, reducing, compiling, recounting, reducing, merging, and reforming. With flexible translation methods, the paper aims to complete good foreign language translation and improve the influence of Chinese culture in world stage.
\end{abstract}

\section{Introduction}

The development of a globalized economic trend has become stronger and stronger, which has promoted trade exchanges among countries in the world and has promoted effective exchanges between cultures in various countries. However, the cultural imbalance between the East and the West has also clearly existed. To promote equal dialogue among cultures, To promote the effective maintenance of national identity and maintain the diversity of the world's culture, it is necessary to promote the dissemination of China's outstanding traditional culture. Intangible cultural heritage is an important component of excellent culture, and the effectiveness of the promotion and translation of non-material cultural heritage is promoted. It is of great significance to promote the dissemination of China's excellent culture. The non-material cultural heritage of the foreign propaganda translation can not only promote the dissemination of excellent traditional culture, promote the effective exchange of national culture, but also promote the effective protection of traditional culture.

\section{Analysis on Current Status of Translation of Non-material Cultural Heritage}

There are more than 30 projects in China listed in the list of intangible cultural heritage, and it is also the country with the largest number of non-material cultural heritage in the world. However, the translation and translation of intangible cultural heritage is still in its infancy. China attaches great importance to the dissemination of its traditional culture to the world. It also pays attention to the dissemination of cultural heritage to the world. Intangible cultural heritage, as an important component of traditional culture, contains the essence of traditional Chinese culture, but due to the huge differences in world culture, China's non-material Some customs and cultures in the cultural heritage may encounter poor translation in the process of translation. Due to cultural differences, the translated contents may have inadequacies, so how to promote translation more accurately in the future translation work Sex is the focus of research. As China's “One Belt, One Road” construction process continues to accelerate, regional development is becoming more in-depth, and exchanges between countries and regions must be effectively strengthened. All regions have begun to pay attention to this rich cultural form of intangible cultural heritage. Research on the Translation of Foreign Propaganda and Promotion of the Effective Research on the Translation and Translation of Non-material Cultural Heritage Projects. 


\section{The Influence of the Main Characteristics of Non-material Cultural Heritage Translation}

A clear and accurate understanding of the intangible cultural heritage's own characteristics is a prerequisite for doing a good job in the translation of foreign propaganda. Intangible cultural heritage is a heritage shared by human beings in a special form. Both its content and its manifestations are very unique, variability, nationality, and richness. It is precisely because of this series of characteristics that there are Make translation work face many difficulties. The biggest difference between intangible cultural heritage and other forms of culture is its intangible nature. Although intangible cultural heritage exists in the form of a material carrier, it still belongs to the category of human behavior and it also needs to be represented by certain behaviors. Therefore, it has brought certain difficulties for the translation work, making it difficult to determine and select the specific content of the translated text. And the nationality and uniqueness of the intangible cultural heritage also make it obvious that there are obvious cultural specific items in the specific translation work, making the translation work more difficult. When we translate Chinese intangible cultural heritage, we must fully integrate our own traditional culture. We also need to ensure that the translated content is compatible with foreign cultural traditions. That is to say, in the process of translation, we need a combination of Chinese and Western cultures, and we need to integrate Chinese and Western cultures. When the culture is integrated into the translation content, it also needs to meet the specific language features of other countries. Such an expression form can be accepted by the world, so that the spirit of the intangible cultural heritage can be effectively disseminated, and the integrity of translation can be effectively preserved. Intangible cultural heritage is a manifestation of culture. Translating culture can promote the effective blending of cultures between countries. This, of course, is also the reason why translation work is difficult. It requires the translation of specific translation content and translation between countries. The language is effectively integrated to ensure that the translated content is valid.

\section{Analysis of Translation Studies of Non-material Cultural Heritage from the Perspective of Translation Studies}

Translatology was originally based on the perspective of media in literature, but now more and more applications of translatology stand in the perspective of comparative culture. Translatology attaches importance to the effectiveness and uniqueness of the specific practical activities of cross-cultural communication, rather than merely focusing on simple transformations between pronunciations at the language level. From the perspective of translation studies, the analysis of the translation of intangible cultural heritage has the intention to effectively promote the translation effect, promote the effective communication and exchange of culture, and promote the effective transmission and protection of culture. From the perspective of translatology, the analysis of the translation of intangible cultural heritage can be conducted in specific ways in the following aspects.

The main body of translation is to discuss the question of who is going to translate. Traditional thinking all believe that translating Chinese content into foreign materials requires foreigners to perform translation work because the target language for translation is the foreign national language. Only the translation work done by foreigners according to the characteristics of their own national language is effective. Promote better communication of the culture you want to spread. However, it has been greatly overlooked, that is, to successfully carry out translation work, we must first establish a full understanding of the translation work so that the translated content is effective. Intangible cultural heritage contains rich cultural characteristics. It is precisely due to the uniqueness of intangible cultural heritage that foreigners have great difficulty in understanding. Even foreigners with better Chinese will understand the content of intangible cultural heritage. There are major difficulties. Therefore, skilled Chinese translators who master foreign languages are the first choice for the translation of intangible cultural heritage, and can promote the translation of intangible cultural heritage to achieve good results. To carry out the translation of intangible cultural heritage requires not only a full understanding of Chinese culture, but also close contact 
with foreign language workers. There are detailed studies and understanding of the language structure of different countries and regions in order to promote culture. It is understood that carrying out the subject translation of intangible cultural heritage requires attention to the intangible cultural heritage itself, rather than focusing on translation issues, so as to facilitate an in-depth understanding of the status of cultural management.

Translation content refers to what is specifically translated. Since the intangible cultural heritage has obvious liveliness, its meta-language determines the specific rendering effect of the foreign propaganda translation. Since most of the items of intangible cultural heritage are presented in practice or in performances, the purpose of disseminating information through outreach and translation needs to allow non-native language learners to understand and recognize these languages, as well as non-material cultures. The translation of the heritage is recognized, the meaning of the translation and the purpose of translation need to be translated by the translator into language. The written material of the intangible cultural heritage does not come from a single person. Some are the inheritors of intangible cultural heritage, and some are homestay folks. They both have distinct styles when writing texts, so they are for the translators. It is also a big challenge. When the specific translation work is carried out, it is necessary to adjust the content of the original text appropriately in accordance with the essential purpose of the translation. In the course of translation, intangible cultural heritage needs to understand the ontology of translation. The translation process needs to fully embody the essence of intangible cultural heritage. Intangible cultural heritage itself needs to integrate into multiculturalism and promote foreign cultural successors to embody various manifestations. The comprehensive absorption of ideas and the display of the results obtained must be in harmony with the intangible cultural heritage itself and ensure that the essence of intangible cultural heritage can be effectively disseminated.

The translation and referral approach refers to how to carry out "introduction". Compared with other publicity materials in other forms of writing, intangible cultural heritage has its own characteristics. Intangible cultural heritage has its own liveness. It is precisely because of this liveness that the means of its dissemination must match the specific description of the text. With the rapid development of society and the continuous development of science and technology, information technology is also continuously developing. Therefore, it is possible to use the advantages brought by information technology to realize the high efficiency of translation and mediation. Promote propaganda work for non-legal translations, and call for social organizations or individuals to actively participate. 4. Research on translation and audience. Translators and audiences refer to the objects of communication. The purpose of the foreign propaganda and translation work is to attract foreign audiences. Therefore, research on the audience is of great significance. The degree of acceptance and understanding of information by the audience reaches the concept of constraints, and the identity of the members of the same cultural group is different from that of culture. The purpose of foreign propaganda translation is foreigners. If you want foreign audiences to understand and accept Chinese culture, you need to promote these differences through translation and intermediaries to achieve effective unity. Translators need to respect both parties' language style and specific expression habits. Try to adopt translations that are acceptable to the audience.

\section{Conclusion}

The foreign propaganda and translation work of intangible cultural heritage can promote the effective dissemination of national culture and realize the national strategy of "going out". How to promote the effectiveness of foreign language translation of intangible cultural heritage is a key research issue for foreign publicity translators. From the perspective of translation studies, it combines the specific characteristics of intangible cultural heritage, conducts in-depth research, and pays attention to multidimensional translation and mediation. The application, taking into account the audience's sense of identity, this way of translation can achieve good results. 


\section{Acknowledgements}

The paper is supported by two projects. The paper is part of the research results of one of the important project of Shandong Province on Arts and Sciences project named "Present Situation and Optimization Strategies of C-E Translation About National Intangible Cultural Heritage in Shandong Province" (Project Number: 201706301); And also, part of the research results of Scientific Research Project in Shandong Youth University of Political Science (Project Number: SQ 2016QN02).

\section{References}

[1] Huang Zhonglian. The Theory of Translation in Translation: A New Translation Theory [J]. Foreign Language Teaching in Foreign Countries, 2002, 1: 1-2.

[2] Huang Zhonglian. Types of Research on Translation Theory [J]. Foreign Language Studies, 2011, 6:1-2.

[3] Wang Qing. The Theory of Translation Translation and Its Application in Translation of Foreign Propaganda [J]. Journal of Shenyang Agricultural University, 2012, 4:1-2.

[4] Wang Linhan. The application of change translation theory in foreign publicity materials [J]. Foreign Language Teaching, 2012, 12:1-2.

[5] Wu Min. Research on the Strategy of Foreign Propaganda Translation of Henan Intangible Cultural Heritage in the Perspective of Adaptation Theory - Taking the Case of the Enamel Porcelain [J]. Journal of Chifeng University, 2016, 10: 1-2. 